\title{
Ecological Optimization for Forecasting Production and Maintenance Problem based on Carbon Tax
}

\author{
Zied Hajej ${ }^{\mathrm{a}-}$, Nidhal Rezg ${ }^{\mathrm{a}-}$, Ali Gharbi ${ }^{\mathrm{b}-}$ \\ a- Laboratoire de Génie Industriel, de Production et de Maintenance, Université de Lorraine - France \\ ${ }^{b-}$ Département de la production automatisée, Ecole de Technologie Supérieure, Montréal - Canada
}

\section{Abstract:}

This paper proposes a new ecological joint production and maintenance policy, which considers an ecological aspect for a forecasting problem of unreliable manufacturing system subject to degradation. The manufacturing system is composed of a single machine producing one product type in order to satisfy a random demand under a given service level. On the other hand, the production system generates harmful emissions to the environment and may be sanctioned by an environmental tax. The objective of this paper is to propose an ecological production and maintenance policy (EPMP) optimization by calling a subcontracting in the context of a calling of tenders in order to satisfy the random demand and to decrease the carbon tax. In this context, we determine the economical production plan and the optimal maintenance strategy by defining a condition for the subcontracting cost in order to respect the EPMP optimization. To illustrate the highlight of the proposed policy, some numerical results are presented.

Keywords: manufacturing system, ecological policy, forecasting production, preventive maintenance, optimization, emission, Carbon Tax.

\section{Introduction}

For industrial manufacturing, the integration of ecological and social aspects with economic considerations has more importance in managerial decision making of the enterprise. This importance will be in terms of products and services that the manufacturer offers and in terms of the processes that the manufacturer deploys. Under this reality, an ecological performance has an important role in the efficiency and traditional performance measures of a manufacturing system. Consequently, the manufacturing system will use their operational strategies to solve and find the solutions of production and maintenance problem by adapting to the random conditions and constraints of the market, and by collaborating, even while integrating environmental concerns. Concerning the environmental aspect (industrial discharges, pollutant 
emissions...) and its influence on the production and maintenance problem in a dynamic stochastic context is ignored in the literature. In this context, (Bonney and Jaber, 2011) showed that there is lack of the economic strategies (production, maintenance...) developed to satisfy waste and toxic emissions standards and requirements while maintaining high economic efficiency.

However, the main problem for manufacturing system is to minimize the production and maintenance costs through the best management but at the same time meets the environmental requirements regulated increasingly by the majority of industrialized countries. Faced to this lack of strategies and the independently addressing both economic and environmental problems, (Kenne and Gharbi, 2000) developed a feedback control policies in a stochastic dynamic environment facing random events for a manufacturing systems and based on Hedging Point Policy (HPP). Subsequently, Based on the concept of HPP, (Gharbi et. al, 2006) developed a Hedging Corridor Policy (HCP) for a joint implementation of a corrective and preventive maintenance strategy and production rate control for a multiple-machine problem.

Recently, Ben Salam et al. (2015) proposed manufacturing strategies that integrate both economic and environmental issue by using a hedging point policy in order to provide a better control of the production rate and the emissions generated. On the other hand, giving the constraints imposed by the environmental requirements in the manufacturing system management and the ambiguity for consideration of harmful emissions in the industry, some works treated this type of industrial environment problem. Among these works, Dobos (1998, 1999, 2001) formulated a mathematical model for a production system, which satisfies demand and determines the impact of environmental policy (taxes, emission penalty or trading permits) on decision variables of system such as production and inventory levels. Li and Gu (2012) minimized the total cost function of manufacturing system production and inventory which the decision variables are the production rate and inventory level and they compared the two policies with and without the environmental requirements. On the other hand, (Battini et al. (2013) treated the production problem using the economic order quantity EOQ model by introducing the environment aspect. Moreover, a few numbers of studies has treated the environmental aspect on the maintenance-planning problem. Among these, Chouikhi et al. $\underline{\text { (2012) }}$ proposed a condition-based maintenance model for a single-unit production system of goods and services. Their maintenance model purposes to evaluate the equipment degradation in order to reduce the deterioration of the environment by performing an inspection and after which the system is preventively replaced or left as it is. They determine an optimal inspection 
dates in order to minimize the average maintenance and reduce environment discharges. Another approach consists of the integration of the environmental issue in an alternative production-maintenance control for manufacturing system subject to degradation. In this sense, Ben Salam et al. (2014) proposed different policies to simultaneously control production rate, emission rate as well as maintenance rate in order to mitigate the effect of the degradation of the system and to minimize the total cost over an infinite horizon.

In our study, we build on Hajej et al. (2014) and Ayed et al. (2012) models. They proposed a new forecasting problem of production and maintenance plan optimization for random demand. In order to satisfy the customer under given service level, it calls upon the subcontracting. They proved the optimal production plans of principal and subcontracting machines, which minimizes the total production, inventory and maintenance cost under constraint that the system failure rate depends on both time and production rate. Concerning the extension of control policy to other manufacturing contexts and considering the subcontractor as solution to resolve the industrial problem, we can cite the work of Dellagi et al.(2007) and Dahane et al. (2010) that they determined an integrated maintenance policies under subcontracting constraint. First work (Dellagi et al. 2007) considered that it is necessary to collaborate with another subcontractor in order to satisfy the customer demand, and other work (Dahane et al. 2010) considered the subcontracting concept in the case of provider of subcontracting service.

The different above-mentioned works have showed the different strategies of controlling manufacturing systems but the consideration of the integration of environmental aspects on an optimization problem of manufacturing system remains an open problem which shows that the combination between the economic efficiency and the ecological aspects has become a necessity. In the light of this reality, the main contribution of this paper is to provide decision makers with manufacturing strategies that integrate both economic and ecological aspect. Thus, a stochastic optimal forecasting production and maintenance control problem of a manufacturing system emitting toxins is considered. The goal is to develop an ecological optimization for production and maintenance strategy in order to determine an economical production planning, an optimal maintenance strategy and emissions penalty, based on subcontractor solution and taking into account that the failure rate of principal machine is correlated with the production.

The paper is organized as follows. Section 2 presents the study contribution. Section 3 proposes the problem statement. In the section 4, a description of the systems dynamic evolution and the proposed production and maintenance policies as well as the ecological production and 
maintenance strategy are presented. Section 5 introduces the optimization model and the proposed resolution approach. A numerical example, a results' interpretation are presented in section 6 . Section 7 concludes the paper.

\section{Study contribution}

It is clear that the ecological constraint is tightly dependent on the maintenance and production strategies adopted. Consequently in our study we exploited the recent important results in the frame of integrated maintenance/production policy established by Hajej et al (2014)) in order to develop a new optimal ecological production and maintenance strategy. The industrial case study upon which this research is based, concerns a steel and mining company located in the Lorraine Region in France. Guided by a philosophy to produce safe, sustainable steel, it is the leading supplier of quality steel products including automotive, construction, household appliances and packaging. The ecological problem for this company is $\mathrm{CO} 2$ emissions which imply tax penalties. Our main contribution for this company is the building of an efficient ecological production and maintenance strategy in order to reduce the Carbone tax penalties and the total cost.

Recall that Hajej et al (2014)) established an optimal integrated maintenance/production policy under subcontractor constraint and taking into account the influence of the production rate variation on the manufacturing system degradation and consequently on the maintenance strategy adopted. In fact, they considered the subcontractor as a solution to satisfy the customer demand with a service level, and to avoid the shortage due to the manufacturing system unavailability. Since, the key of our study consists in establishing new ecological production and

maintenance strategy based on subcontractor solution in the context of a calling of tender taking into account the degradation degree of equipment knowing that it is modulated to rates of production. We recall that a part of our study is based on some results obtained in the work of Hajej et al (2014)).

\section{Problem statement}

In order to formulate the analytical model of the problem we will introduce in the next section some notations.

\subsection{Notations}

The following notations are used:

$H$ : period number of the finite production horizon 
$\Delta \mathrm{t}$ : length of period $k$

$\mathrm{S}(\mathrm{k})$ : inventory level at the end of the period $k(\mathrm{k}=1, \ldots \ldots, \mathrm{H} / \Delta \mathrm{t})$

$\mathrm{u}(\mathrm{k})$ : production rate level at period $k$

$\mathrm{d}(\mathrm{k})$ : demand level at period $k$

$Q_{c}^{A}(0)$ : quantity of carbon credits (quantity of emissions) allocated for period $L$ by the authorities.

$X$ : the quantity of harmful emissions generated by one manufactured product (one article)

Cpr : unit production cost

$\mathrm{Ch}_{\mathrm{h}}$ : holding cost of a product unit during the period $k$

Cs: subcontracting cost

$f(t)$ : probability density function of time to failure for the machine

$\mathrm{R}(\mathrm{t})$ : reliability function

$\lambda(\mathrm{t})$ : system failure rate, depending on both time and production rate

Mp: unit preventive maintenance action cost

Mc: unit corrective maintenance action cost

mu: monetary unit

Umax: maximal production rate

$J$ : total expected cost of production and inventory over the finite horizon $\mathrm{H}$

CM: total maintenance cost

$\theta:$ probabilistic index (related to customer satisfaction)

Cc: the unit cost of the emissions penalty

\subsection{Problem description}

The manufacturing system considered in this study, consists of a single machine $M$ producing one type of product to satisfy a random demand from a finished product stocking area with a given service level and during a finite production horizon. The customer demand is assumed to be specified by a normal distribution. The machine $M$ is subject to a random failures, repairs and maintenance activities. The probability density function associated with its time to failure is $f(\mathrm{t})$ and its failure rate, $\lambda(t)$, increases with both time and production rate $u(t)$. Among the characteristics of the manufacturing system under study, harmful emissions are generated during the production. On the other hand, the manufacturing system production causes 
damaging emissions to the environment and may incur sanctions in the form of an ecological tax imposed by the relevant authorities. We consider that the production of one article causes the release of a quantity of pollutant. Consequently, the company is subject to a respect for environmental clauses related to the carbon tax. In this case, it can be assumed under the clause that the emission cap approach where authorities can impose a standard emission limit or a specific quantity of carbon equals to $Q_{c}^{A}$ per period $L$ and at each exceeding of $Q_{c}^{A}$ for all future production, a penalty related to the carbon tax should be paid for each emission unit. The company can also make a call to subcontracting in order to meet demand and to ensure that the fixed level of service, at the same time can be a solution to minimize of Carbon tax to pay. Let Cc and Cs corresponds respectively to the cost of the emissions penalty related to the carbon tax (carbon / monetary unit) and the cost of an article subcontracted.

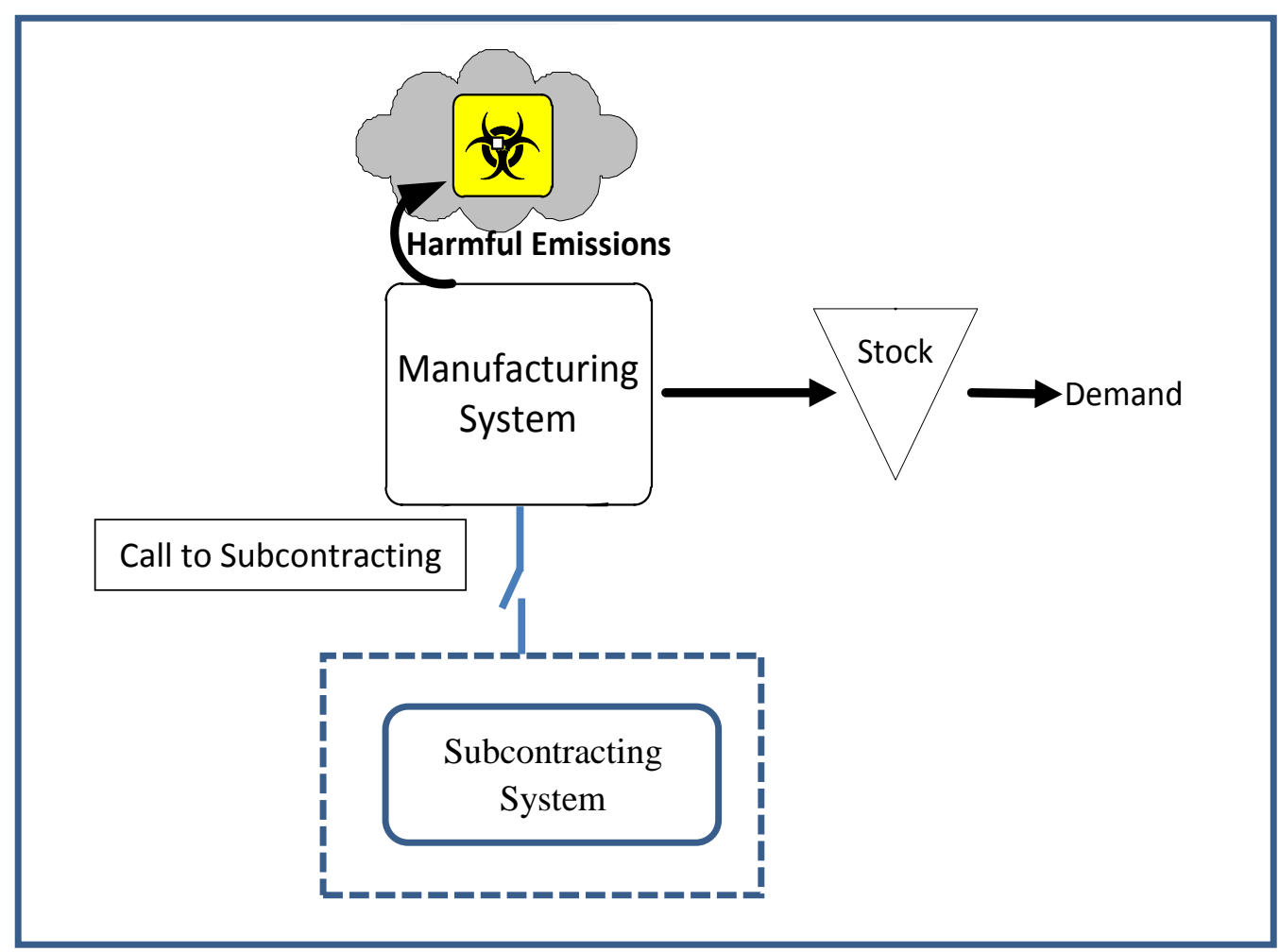

Figure 1: System under study.

Since the significant compromise must take place between production, maintenance and emissions penalty costs, the main objective is to call a subcontracting in the context of a calling of tender, where the cost Cs has to be fixed from optimization called EPMP (Ecological Production and Maintenance Policy) whose reference is the solution of purchase carbon credits by paying the penalties Cc. 
The main questions to answer in our problematic are: What will be the cost of subcontracting Cs in order to respect the EPMP optimization? Recall that apart that penalties for carbon tax of production higher than Qc, there was also the degradation of production equipment that must be taken into account knowing it is modulated at production rates.

\section{Production and Maintenance policies}

\subsection{Description}

We recall that in our study, the production horizon is partitioned equally into $H$ periods. Every period is noted by $k, k=\{1,2, . . \mathrm{H}\}$. The demand variable $\mathrm{d}(\mathrm{k})$ must be understood as being a stochastic component of the inventory balance system. Particularly, the evolution of demand over the periods follows a Normal distribution where the independent random variables $\mathrm{d}(\mathrm{k})$ have mean $E\left(d_{k}\right)=\hat{d}_{k}$ and time-invariant variance $\operatorname{Var}\left(d_{k}\right)=\sigma_{d}^{2}$. It's worth emphasizing that such process has been used in practice, to represent product demands determined by a prior forecasting device or even from historical data related to customers' orders. We noted that the demand is satisfied at the end of each period.

\subsection{Analytical formulation}

The idea is to minimize the expected production, inventory and maintenance costs over a finite time horizon $[0, H . \Delta t]$. The demand must be satisfied at the end of each period. This kind of problem can be formulated as a stochastic optimal control problem under threshold inventory level constraint. For the considered manufacturing system, $S(k)$ and $u(k)$ denote the inventory level and the production rate of the system.

For any specific period $k$, the state of the system has a continuous component describing the inventory cumulative level at each period $k$. Hence, the inventory balance level at period $k+1$ is equals to the inventory level at the previous period (i.e. The period $k$ ), plus the number of products produced by machine $M$ in the previous period $\mathrm{k}$, minus the quantity of products requested by the customer at the period $\mathrm{k}$.

The dynamic behavior of the inventory level is given by the following equation:

$$
S(k+1)=S(k)+u(k)-d(k), \quad S(0)=S_{0} \text { with } k \in\{0,1, \ldots, H-1\}
$$

where $S_{0}$ denotes the initial inventory level.

The service level, characterized by a probabilistic constraint related to inventory, is taken as a chance-constraint. The uncertainty about fluctuation of the demand brings randomness to the 
first constraint (1) of inventory balance equation. Therefore, the inventory and production variables are stochastic and their statistics depend on the probabilistic distribution functions of demand. This explains the use of probabilistic constraint (2). Such a constraint can also be useful to help manager to analyze diverse situations and scenarios of production. For example, by varying the value of probabilistic index $\theta$ in (2), the manager can analyze various storage policies and therefore look forward to improving customer satisfaction.

Formally the service level constraint for each period is presented as follows:

$$
\operatorname{Prob}\lfloor S(k+1) \geq 0\rfloor \geq \theta \text { with } k \in\{0,1, \ldots, H-1\}
$$

The machine capacity constraint takes into account the consumption of carbon credit. Let $B_{c}(k)$ be the indicator of carbon of every period $k$ expressed as the binary variable. The production rate of every period $k$ cannot exceed the given maximal production rate $U^{\max }$ if the indicator of carbon $B_{c}(k)$ equals to 1 in the case where the amount consumed for carbon credits $Q_{c}(k)$ at period $k$ higher than 0 , otherwise, the indicator of carbon equals to 0 .

The production rate at any given time must satisfy the capacity constraint of the system given by equation:

$$
0 \leq u(k) \leq U^{\max } \cdot B_{c}(k) \quad \text { with } B_{c}(k)=\left\{\begin{array}{ccc}
1 & \text { si } Q_{c}(k)>0 \\
0 & \text { si } Q_{c}(k) \leq 0
\end{array} \text { with } B_{c}(k)\right. \text { : Indicateur carbone }
$$

When producing parts at a variable rate $u(t)$, the system is constrained to emit a quantity of harmful pollutants for each part produced. On the other hand, the manufacturing system under study must comply with the standards and rules which stipulates that in each reference period $j$, if the quantity of emissions or the consumption for carbon exceeds a standard level fixed by the relevant authorities, the excess quantity is penalized with an environmental cost (Jaber et al. 2013). At the end of the reference period, the emission counter is reset to zero.

Therefore, the remaining amount of carbon at period $j . \Delta t$ is given by the following equation:

$$
Q_{c}(j)=Q_{c}(0)-\sum_{k=1}^{j} u(k) \cdot \Delta t \cdot X \text { with } \begin{cases}Q_{c}(0)=Q_{c}^{A}(0) \cdot H / L & \text { si } H / L \geq 1 \\ Q_{c}(0)=Q_{c}^{A}(0) & \text { si } H / L<1\end{cases}
$$

Where:

$Q_{c}^{A}(0)$ : quantity of carbon credits (quantity of emissions) allocated for period $L$ by the authorities.

$X$ : quantity of harmful emissions generated by one manufactured product (one article) 


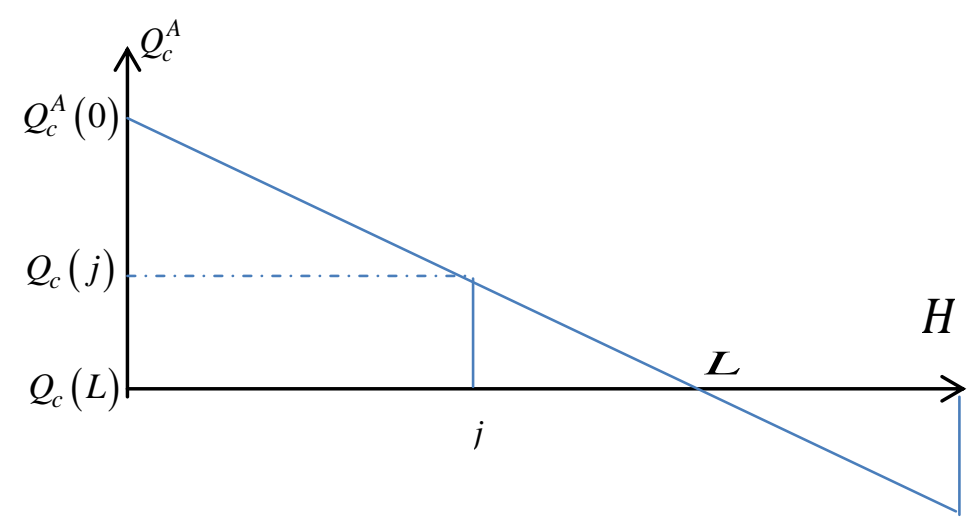

Figure 2: Evolution of Carbon quantity during the horizon $\mathrm{H}$

\subsubsection{Production and Inventory Cost}

The production and maintenance model is strongly conditioned by the involved costs defined in the following equations.

For each period $k$, From Hajej et al. (2011), we calculate the inventory cost according to the inventory level $S(k)$ and based on HMMS model that use a quadratic cost function which allows penalizing both excess and shortage in the inventory level. The cost function is given by the following equation:

$$
g\left(S(k)=C_{s} \times E\left\{S(k)^{2}\right\}\right.
$$

Where $E\{\}$ denotes the mathematical expectation operator.

The expected production cost for each period is given by the following equation:

$$
f(u(k))=C_{p r} \times E\left\{u(k)^{2}\right\}
$$

Using the equations (5) and (6), the total expected production and holding cost $J($.$) over the finite$ horizon $H . \Delta \mathrm{t}$ can be defined by the following equation:

$J(u, S)=\sum_{k=0}^{H} J_{k}(u(k), S(k))=C_{s} \times E\left\{S(H)^{2}\right\}+\sum_{k=0}^{H-1}\left[C_{s} \times E\left\{S(k)^{2}\right\}+C_{p r} \times E\left\{u(k)^{2}\right\}\right] \quad$ with $k \in\{0,1, \ldots, H-1\}$

\subsubsection{Maintenance Cost}


Recall that, the manufacturing system studied is subject to random failures and repair actions and maintenance activities. Over a given finite horizon $H . \Delta t$ divided equally into $N$ parts of duration T. A perfect maintenance (overhaul) restores the degradation effects and makes the system as new (AGAN) at times $h . T(h=1,2, \ldots, N)$. When the unit fails between successive perfect maintenance, a corrective maintenance operation is carried out. This type of minimal repair restores the system to the same state as before failure (ABAO) since the corrective maintenance has no influence on the degradation state of the system. It is assumed that the repair and perfect maintenance durations are negligible.

The correlation of the system degradation and the production rate is established by the increasing of failure rate on function to both time and the production rate (Hajej et al. 2010). The objective of the maintenance strategy is to determine the optimal maintenance planning characterized by the optimal number $\mathrm{N}^{*}$ of preventive maintenance operations during the finite production horizon $\mathrm{H} . \Delta \mathrm{t}$.

Analytically, the maintenance cost is expressed as follows:

$$
C_{M}(U, N)=C_{p m} \times(N-1)+C_{c m} \times \varphi_{M}(U, N)
$$

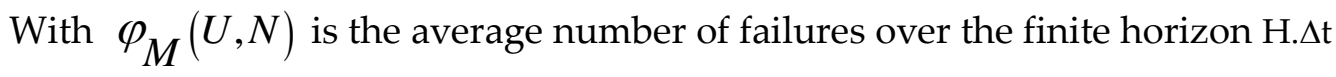

\section{$\underline{\text { 4.2.3 Ecological Production and Maintenance Strategy }}$}

In this section, we present a joint production and maintenance optimization strategy in ecological context. The control of the manufacturing system under study will confront the manager with the need for an important trade-off between the costs of emission (carbon tax), production, inventory and maintenance. The way to tackle the problem will be to give a party of production to the subcontractor but on condition that the cost of subcontracting will be more economical than the cost of the tax carbon to be paid if we want to produce this production part. This decision cannot be taken independently of the inventory cost and maintenance cost because when we subcontract some production we will minimize the cost of inventory and maintenance. The principle of this strategy is to determine the quantity of production, which will be given to subcontracting in order to avoid paying more carbon tax and to determine the economic subcontracting price to minimize the total cost. In this case, we determined the quantity of carbon consumption exceeding the quantity of carbon credits allocated by the authorities by calculating the difference between $Q_{c}^{A}(0)$ and the consumed quantity at the end of finite production horizon H. $\Delta \mathrm{t}$ that equals to $Q_{c}(H)$. Subsequently, we considered two costs $C_{1}$ and $C_{2}$. Firstly cost $\left(C_{1}\right)$ is the summation of no ecological production and maintenance policy cost $C(\overline{E P M P})$, where we considered only the cost of production, inventory and maintenance (without the cost of carbon tax and without subcontracting cost), and the cost of carbon tax. The second cost $\left(C_{2}\right)$ is the cost of no ecological production and maintenance policy $C(\overline{E P M P})$ plus subcontractor cost minus the costs of production, inventory and maintenance correspond to this 
quantity of carbon consumption exceeding $Q_{c}^{A}(0)$ ( to be out when using the subcontractor). This policy is a commitment, which considers the determination of an analytical condition by comparing the two costs and setting a specific limit of subcontracting cost from which we obtain an optimal total cost under ecological aspects.

Formally, we assumed that:

$C(\overline{E P M P}):$ cost of no ecological production and maintenance policy

$\overline{C_{M}(U, N)}$ : maintenance cost to remove from $C_{M}(N, U)$ when called the subcontracting

With:

The first cost $\left(\mathbf{C}_{\mathbf{1}}\right)$ where we considered the cost of carbon tax but not subcontractor cost is given by following equation:

$$
C_{1}=C(\overline{E P M P})+\Delta Q_{c} \cdot C c
$$

With $C c$ : the cost of the emissions penalty

And $\Delta Q_{c}$ is the quantity of carbon consumption exceeding the quantity of carbon credits allocated by the authorities:

$$
\Delta Q_{c}=Q_{c}^{A}(0)-Q_{c}(H)
$$

The second cost $\left(\mathbf{C}_{2}\right)$ where we considered the subcontractor:

$$
C_{2}=C(\overline{E P M P})-\overline{C_{M}(N, U)}-C_{p r} \cdot \Delta p-C_{h} \cdot \sum_{j=L+1}^{H} E\{S(j)\}^{2}+C_{s} \cdot \Delta P
$$

According to equation 10, we can determine the quantity of product $\Delta P$ correspond to $\Delta Q_{c}$ is expressed as follows:

$$
\Delta P=\left(Q_{c}^{A}(0)-Q_{c}(H)\right) / X
$$

Recall that X: quantity of harmful emissions generated by one manufactured product

The cost of subcontracting $C_{s}$ in order to respect the EPMP optimization is given by the following lemma:

\section{Lemma:}

The maximal value of subcontracting cost $C_{S}$ for accepted the tender of subcontractor is given by: 


$$
C_{2}-C_{1}<0 \Rightarrow C_{s} \leq \frac{\Delta Q_{c} \cdot C c+\overline{C_{M}(N, U)}+C_{p r} \cdot \Delta p+h \cdot \sum_{j=l+1}^{H} E\{S(j)\}^{2}}{\Delta P}
$$

Proof:

$$
\begin{gathered}
C_{1}=C(\overline{E P M P})+\Delta Q_{c} \cdot C c \\
C_{2}=C(\overline{E P M P})-\overline{C_{M}(N, U)}-C_{p r} \cdot \Delta p-h \cdot \sum_{j=l+1}^{H} E\{S(j)\}^{2}+C_{s} \cdot \Delta P \\
C_{2}-C_{1}<0 \\
\Rightarrow(\overline{E P M P})-\overline{C_{M}(N, U)}-C_{p r} \cdot \Delta p-C_{h} \cdot \sum_{j=l+1}^{H} E\{S(j)\}^{2}+C_{s} \cdot \Delta P-C(\overline{E P M P})-\Delta Q_{c} \cdot C c \leq 0 \\
-\overline{C_{M}(N, U)}-C_{p r} \cdot \Delta p-C_{h} \cdot \sum_{j=L+1}^{H} E\{S(j)\}^{2}+C_{s} \cdot \Delta P \leq \Delta Q_{c} \cdot C c \\
C_{s} \cdot \Delta P \leq \Delta Q_{c} \cdot C c++\overline{C_{M}(N, U)}+C_{p r} \cdot \Delta p+C_{h} \cdot \sum_{j=l+1}^{H} E\{S(j)\}^{2} \\
C_{s} \leq \frac{\Delta Q_{C} \cdot C c+C_{p r} \cdot \Delta p+\overline{C_{M}(N, U)}+C_{h} \cdot \sum_{j=l+1}^{H} E\{S(j)\}^{2}}{\Delta P}
\end{gathered}
$$

\section{Optimization Model and Solution Method}

The main purpose of this section is to propose an optimization model for minimizing the total cost over the finite horizon H. $\Delta \mathrm{t}$ and present a new method for solving this model. The transforming from stochastic problem defined above into an equivalent deterministic problem facilitates the resolution of our sequential stochastic linear programming problem under constraints.

\section{$\underline{5.1 \text { Equivalent deterministic problem }}$}

Recall that the demand variable $\mathrm{d}(\mathrm{k})$ is normally distributed with mean $E(d(k))=d(k)$ and standard deviation $\sigma_{d, k}$ known for each period $k$ and the inventory variable $S(k)$ is statistically described respectively by its mean $E(S(k))=S(k)$ and variance $E\left((S(k)-S(k))^{2}\right)=\operatorname{Var}(S(k))$ Since $\mathrm{u}(\mathrm{k})$ is constant for each production period $\Delta \mathrm{t}$, we have $u(k)=E(u(k))=u(k)$ and $\operatorname{Var}(u(k))=0$ and the equivalent inventory balance is given by the following equation: 


$$
S(k+1)=S(k)+u(k)-d(k) \quad \text { with } k \in\{0,1, \ldots, H-1\}
$$

\section{- $\quad$ Function of production and inventory cost}

From Hajej et al. (2011), we established that $\operatorname{Var}(S(k))=E\left(S(k)^{2}\right)-S(k)^{2}$. Assuming that the standard deviation is constant for each production period $k$ and equals to $\sigma_{d}$ and $\operatorname{Var}(S(0))=0$, we have

$$
\begin{gathered}
\operatorname{Var}(S(k))=k \times\left(\sigma_{d}\right)^{2} \\
\text { And } \\
E\left(S(k)^{2}\right)=k \times\left(\sigma_{d}\right)^{2}+S(k)^{2}
\end{gathered}
$$

By substituting the relation (16) on the total cost of production and inventory (7), we obtained the equivalent deterministic function:

$$
J(u, S)=C_{s} \hat{S}(H)^{2}+\sum_{k=0}^{H-1}\left[C_{h} \cdot \hat{S}(k)^{2}+C_{p r} \cdot u(k)^{2}\right]+C_{s}\left(\sigma_{d}\right)^{2} \frac{H(H+1)}{2}
$$

Where $\hat{S}(k)$ represents the mean stock level at the end of period $k$.

\section{- Deterministic equivalent service level constraint:}

We transform the stochastic service level constraint in a deterministic form by specifying a minimum cumulative production quantity depending on the service level requirements. From the analytically expression of the variance of inventory variable defined in equation 15 . The random inventory variable $\mathrm{S}(\mathrm{k})$ expressed by the following relation:

$$
S(k)=S(k)+\varepsilon_{k} \times \sqrt{\operatorname{Var}(S(k))} \Leftrightarrow S(k)=S(k)+\varepsilon_{k} \times \sqrt{k} \times \sigma_{d}
$$

Where $\varepsilon_{k}$ follows the standard normal deviate $N(0,1)$.

This deterministic constraint of service level (1) is expressed as follows:

$$
u(k) \geq \varphi^{-1}(\theta) \times \sqrt{k+1} \times \sigma_{d}-S(k)+d(k) \quad \text { with } k \in\{0,1, \ldots, H-1\}
$$

$\varphi$ : Normal Cumulative distribution function with mean $\mu=0$ and standard deviation $\sigma=1$

$\varphi^{-1}$ : the quantile function of the standard normal distribution

\section{- $\quad$ Function of maintenance cost}

The objective of the maintenance strategy optimization is to determine the optimal maintenance plan characterized by the optimal number $\mathrm{N}^{*}$ of preventive maintenance actions, and the time between them $\mathrm{T}^{*}$, as given by Eq. 


$$
T^{*}=\frac{H}{N^{*}}
$$

Recall that the analytical expression of maintenance cost defined in equation (8) is:

$$
C_{M}(U, N)=C_{p m} \times(N-1)+C_{c m} \times \varphi_{M}(U, N)
$$

The failure rate of the machine progresses in each production period according to the production rate. From Hajej et al. (2011), the failure rate in the each interval $k$ is expressed as following:

$$
\lambda_{k, j}(t)=\lambda_{k-1, j}(\Delta t)+\frac{U_{k, j}}{U_{\text {max }}} \lambda_{n}(t) \quad \forall t \in\lfloor 0, \Delta t\rfloor \text { and } \forall j \in\lfloor 0,1, \ldots ., N\rfloor
$$

Where $j$ presented the interval of maintenance actions

With $\lambda_{k, j=0}=\lambda_{0, j}$ and $\Delta \lambda_{k, j}(t)=\frac{U_{k, j}}{U_{\max }} \lambda_{n}(t)$

And $\lambda_{n}(t)$ is the nominal failure rate corresponding to failure of machine works with its maximal production rate during the all horizon $\mathrm{H} . \Delta \mathrm{t}$

We can simplify the expression of the failure rate as follows

$$
\lambda_{k, j}(t)=\lambda_{0, j}+\sum_{l=1}^{k-1} \frac{U_{l, j}}{U_{\max }} \lambda_{n}(\Delta t)+\frac{U_{k, j}}{U_{\max }} \lambda_{n}(t) \text { with } t \in[0, \Delta t]
$$

Let In denote the integer part of (.). Then the average failure number over the horizon $\mathrm{H} . \Delta \mathrm{t}$ is:

$$
\begin{aligned}
\varphi_{M}(U, N)=\sum_{j=0}^{N-1}\left[\sum_{i=\operatorname{In}\left(j \times \frac{T}{\Delta t}\right)+1}^{\operatorname{In}\left((j+1) \times \frac{T}{\Delta t}\right)} \int_{0}^{\Delta t} \lambda_{i, j}(t)\right. & +\int_{0}^{(j+1) \times T-\operatorname{In}\left((j+1) \times \frac{T}{\Delta t}\right) \times \Delta t} \lambda_{\ln \left((j+1) \times \frac{T}{\Delta t}\right)+1, j}(t) d t \\
& \left.+\int_{0}^{\left(\operatorname{In}\left((j+1) \times \frac{T}{\Delta t}\right)+1\right) \times \Delta t-(j+1) \times T} \frac{\left(u\left(\operatorname{In}\left((j+1) \times \frac{T}{\Delta t}\right)+1\right)\right)}{U_{\max }} \times \lambda_{n}(t) d t\right]
\end{aligned}
$$

Therefore, we replace $\lambda_{i}(t)$ in the expression (23): 


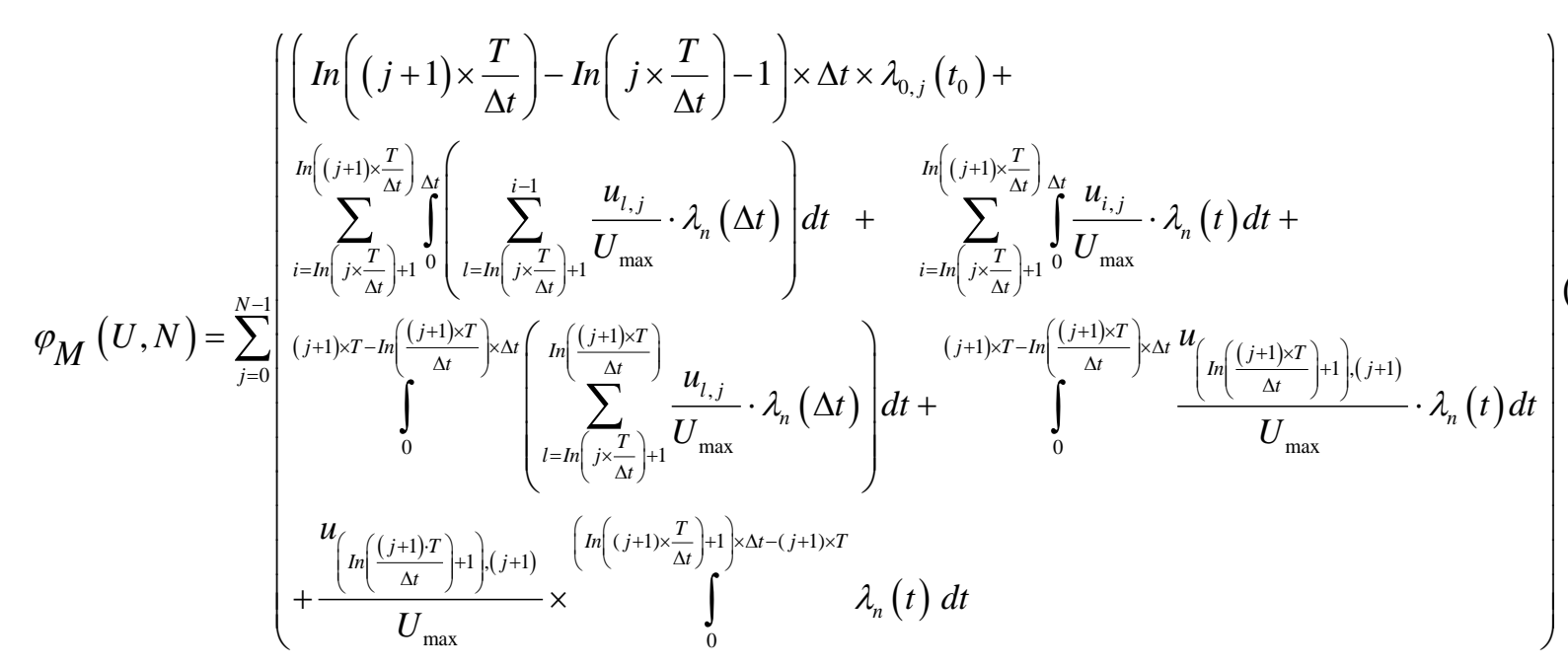

We now replace $\mathrm{T}=\mathrm{H} / \mathrm{N}$ :

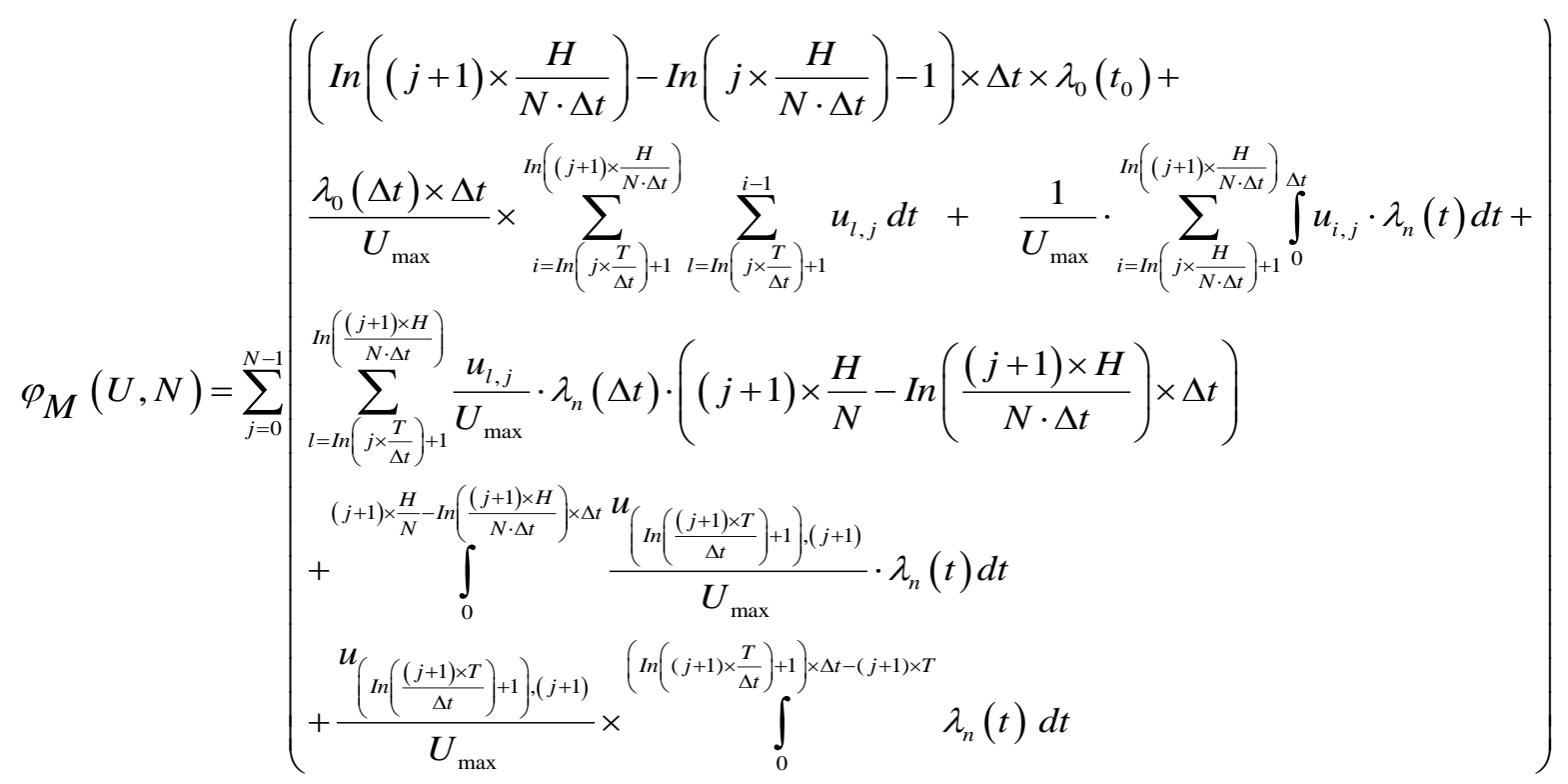

\section{$\underline{5.2 \text { Ecological production and maintenance optimization }}$}

In order to define in the tender a minimal subcontractor cost $C_{S}$, the purpose is to minimize the maintenance cost $\overline{C(N, U)}$ that remove from $C_{M}(N, U)$ when we call the subcontracting and that depend on the number of failure correlated with production rates $u(k)$ for each period $k$. The call for subcontracting will be a load optimization in production rates in order to minimize the number of failure and consequently to minimize the quantity of maintenance cost to remove $\overline{C(N, U)}$ from the global cost $C(N, U)$ if the quantity $\Delta P$ is assigned to subcontracting.

The dispatching in the subcontracting is done using the following logic : $\operatorname{Min}_{U->S} \overline{C(N, U)}$ 
In this case, the strategy consists of determination of the optimal number of preventive maintenance actions $N^{*}$ and the optimal interval between two successive maintenance actions $T^{*}$. Thereafter, we calculate the average number of failure for each interval $([0, T],[\mathrm{T}, 2 . T], \ldots . .[(\mathrm{N}-$ 1)T, N.T) with N.T=H. We tried in this strategy to compare the result of the minimal subcontractor cost $C_{s}$ of two proposals by dispatching the production quantity $\Delta P$ for the subcontracting according to ascending or descending order of average number of failure. In the case of descending order, we remove the production quantity $\Delta P$ from the production periods which are in the maintenance interval [(i-1).T, i.T] where there are the largest average number of failures. The case of ascending order is to remove $\Delta P$ from the production periods, which are in the maintenance interval where there the smallest average number of failures exist.

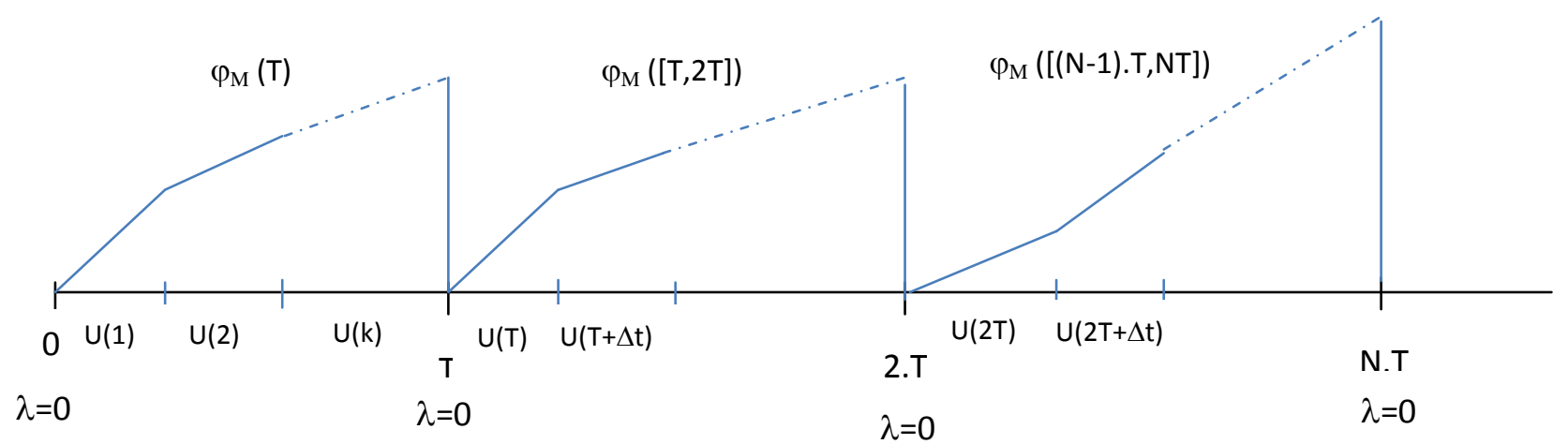

Figure 3: Evolution of average number of failure

\section{Numerical Experiment}

In order to illustrate the model developed previously, we consider that a manufacturing system produces one product type whose demand fluctuates periodically. The planning horizon $\mathrm{H}=24$ periods with production period $\Delta \mathrm{t}=1 \mathrm{um}$, the failure time of machine $\mathrm{M}$ characterized by a Weibull distribution with increasing failure rate. The main data of the problem are the monthly mean demands $d(k)$ given by the Table 1; $C_{p r}=3 \mathrm{mu}, C_{h}=2 \mathrm{mu}, U^{\max }=15 \mathrm{mu}, Q_{c}^{A}(0)=15, \mathrm{X}=2$, $\mathrm{C}_{c}=12, \mathrm{C}_{\mathrm{s}}=20, \mathrm{~S}(0)=20$, the variance of demand $V_{d}=1.42$, the degree of customer satisfaction, associated with the service level constraint is equal to $90 \%(\theta=0.9)$.

Table 1: AVERAGE DEMAND

\begin{tabular}{|c|c|c|c|c|c|c|c|}
\hline$d(1)$ & $d(2)$ & $d(3)$ & $d(4)$ & $d(5)$ & $d(6)$ & $d(7)$ & $d(8)$ \\
\hline 10 & 13 & 9 & 6 & 6 & 5 & 12 & 7 \\
\hline$d(9)$ & $d(10)$ & $d(11)$ & $d(12)$ & $d(13)$ & $d(14)$ & $d(15)$ & $d(16)$ \\
\hline 11 & 11 & 9 & 11 & 3 & 10 & 14 & 4 \\
\hline$d(17)$ & $d(18)$ & $d(19)$ & $d(20)$ & $d(21)$ & $d(22)$ & $d(23)$ & $d(24)$ \\
\hline 14 & 9 & 14 & 1 & 9 & 2 & 11 & 15 \\
\hline
\end{tabular}

The optimal production plan is obtained, using a numerical algorithm for Constrained Global Optimization with MATHEMATICA, which is presented in tables 2. According to the production plan for machine $\mathrm{M}$ obtained, we have observed, for maintenance policy, the optimal number of preventive maintenance interval $N^{*}$ and the time of preventive maintenance action $T^{*}$ with $T^{*}=H / n^{*}$. 
Table 2: OPTIMAL PRODUCTION PLAN

\begin{tabular}{|c|c|c|c|c|c|c|c|}
\hline$u^{*}(1)$ & $u^{*}(2)$ & $u^{*}(3)$ & $u^{*}(4)$ & $u^{*}(5)$ & $u^{*}(6)$ & $u^{*}(7)$ & $u^{*}(8)$ \\
\hline 0 & 5 & 10 & 10 & 1 & 10 & 11 & 10 \\
\hline$u^{*}(9)$ & $u^{*}(10)$ & $u^{*}(11)$ & $u^{*}(12)$ & $u^{*}(13)$ & $u^{*}(14)$ & $u^{*}(15)$ & $u^{*}(16)$ \\
\hline 7 & 13 & 8 & 8 & 8 & 10 & 12 & 13 \\
\hline$u^{*}(17)$ & $u^{*}(18)$ & $u^{*}(19)$ & $u^{*}(20)$ & $u^{*}(21)$ & $u^{*}(22)$ & $u^{*}(23)$ & $u^{*}(24)$ \\
\hline 12 & 9 & 3 & 7 & 2 & 5 & 13 & 12 \\
\hline
\end{tabular}

From equation (4), The plan of carbon consumption for each production period and during the finite horizon $\mathrm{H}=24$ is given by the Table 3 . The quantity of carbon consumption exceeding the quantity of carbon credits allocated by the authorities during the finite horizon $H . \Delta t$, is equal to $\Delta Q_{c}=33$ (equation 10) and the quantity of product correspond to $\Delta Q_{c}$ is equal to $\Delta P=16$ (equation 12). Consequently, the cost of carbon tax $\Delta Q_{c} . C c$ is equals to $192 \mathrm{um}$.

Table 3: CARBON CONSUMPTION PLAN

\begin{tabular}{|c|c|c|c|c|c|c|c|}
\hline$Q_{c}(1)$ & $Q_{c}(2)$ & $Q_{c}(3)$ & $Q_{c}(4)$ & $Q_{c}(5)$ & $Q_{c}(6)$ & $Q_{c}(7)$ & $Q_{c}(8)$ \\
\hline 13 & 11 & 9 & 7 & 5 & 3 & 1 & -1 \\
\hline$Q_{c}(9)$ & $Q_{c}(10)$ & $Q_{c}(11)$ & $Q_{c}(12)$ & $Q_{c}(13)$ & $Q_{c}(14)$ & $Q_{c}(15)$ & $Q_{c}(16)$ \\
\hline-3 & -5 & -7 & -9 & -11 & -13 & -15 & -17 \\
\hline$Q_{c}(17)$ & $Q_{c}(18)$ & $Q_{c}(19)$ & $Q_{c}(20)$ & $Q_{c}(21)$ & $Q_{c}(22)$ & $Q_{c}(23)$ & $Q_{c}(24)$ \\
\hline-19 & -21 & -23 & -25 & -27 & -29 & -31 & -33 \\
\hline
\end{tabular}

For the maintenance policy, the scale and shape parameters of the Weibull distribution are exhibited, respectively, $\alpha=2$ and $\beta=100$, while the unit corrective maintenance cost $M c=3000$ $\mathrm{mu}$ and the unit preventive maintenance cost $M p=500 \mathrm{mu}$. Figure 4 presents the curve of the total maintenance cost according to $N$. We conclude that the optimal number of preventive maintenance periods is $N^{*}=4$. Performing overhauls every $\mathrm{T}^{*}=6 \mathrm{tu}$, corresponds to a minimal total cost of maintenance action $\mathrm{C}_{\mathrm{M}}{ }^{*}=1368,96 \mathrm{mu}$ (monetary units). According to the maintenance strategy, Table 4 given the average number of failure for each interval of maintenance $[\mathrm{i} . \mathrm{T},(\mathrm{i}+1) . \mathrm{T}]$ with $\mathrm{i} \in\{0,1,2,3\}$ 


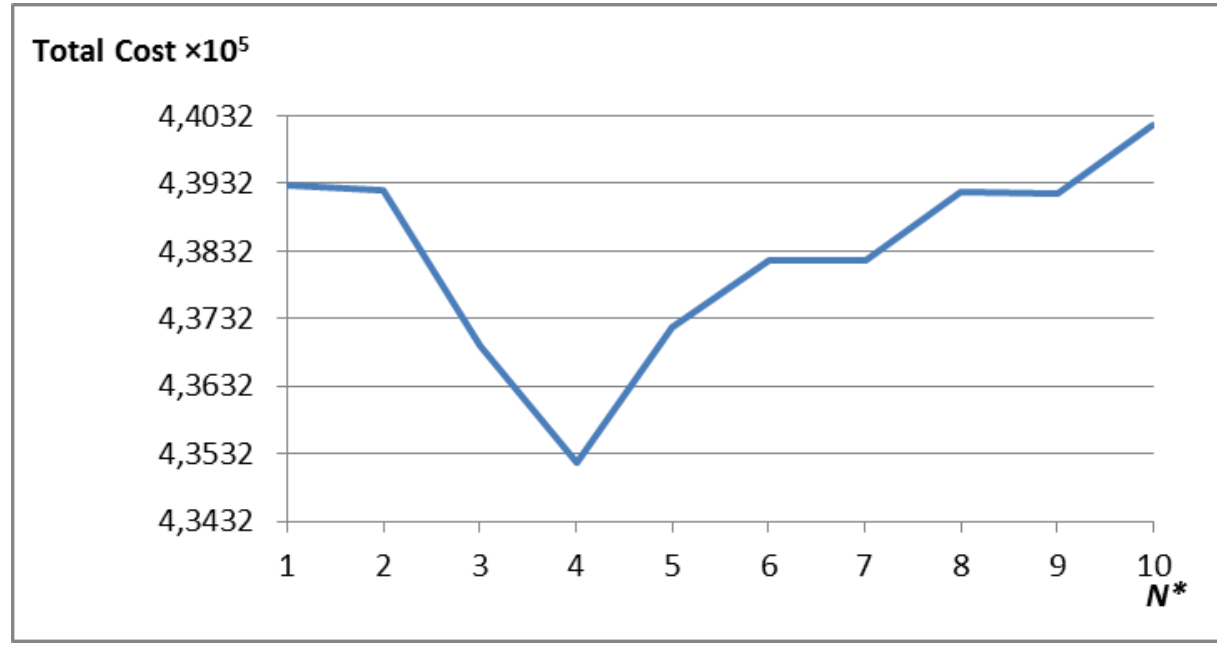

Figure .4. Curve of total cost of maintenance according to $\mathrm{N}$

Table 4: AVERAGE NUMBER OF FAILURE

\begin{tabular}{|c|c|c|c|c|c|c|c|}
\hline \multicolumn{8}{|c|}{ Maintenance Interval $[i . \mathrm{T},(i+1) . \mathrm{T}]$} \\
\hline \multicolumn{8}{|c|}{ Average number of failure } \\
\hline \multicolumn{8}{|c|}{ production rates in the maintenance interval } \\
\hline \multicolumn{4}{|c|}{$[0, \mathbf{T}]$} & \multicolumn{4}{|c|}{$[\mathrm{T}, 2 \mathrm{~T}]$} \\
\hline \multicolumn{4}{|c|}{14,83634} & \multicolumn{4}{|c|}{9,98135} \\
\hline $\mathbf{u}(0)=0$ & $\mathbf{u}(\mathbf{1})=5$ & $\mathbf{u}(\mathbf{2})=10$ & $\mathbf{u}(3)=\mathbf{1 0}$ & $\mathrm{u}(4)=1$ & $u(5)=10$ & $\mathrm{u}(6)=11$ & $\mathrm{u}(7)=10$ \\
\hline \multicolumn{4}{|c|}{$[2 \mathrm{~T}, 3 \mathrm{~T}]$} & \multicolumn{4}{|c|}{$[3 \mathrm{~T}, 4 \mathrm{~T}]$} \\
\hline \multicolumn{4}{|c|}{9,99256} & \multicolumn{4}{|c|}{9,99766} \\
\hline$u(8)=7$ & $u(9)=13$ & $u(10)=8$ & $\mathrm{u}(11)=8$ & $\mathrm{u}(12)=8$ & $\mathrm{u}(13)=10$ & $\mathrm{u}(14)=12$ & $\mathrm{u}(15)=13$ \\
\hline \multicolumn{4}{|c|}{$[4 \mathrm{~T}, 5 \mathrm{~T}]$} & \multicolumn{4}{|c|}{$[5 \mathrm{~T}, 6 \mathrm{~T}]$} \\
\hline \multicolumn{4}{|c|}{10,00198} & \multicolumn{4}{|c|}{9,99519} \\
\hline$u(16)=12$ & $\mathrm{u}(17)=9$ & $u(18)=3$ & \begin{tabular}{|l|l}
3 & $u(19)=7$
\end{tabular} & $\mathrm{u}(20)=2$ & $\mathrm{u}(21)=5$ & $\mathrm{u}(22)=13$ & $u(23)=12$ \\
\hline
\end{tabular}

For the first approach characterized by descending order defined in table 5, we start by removing the production quantity $\Delta P=\mathbf{1 6}$ from the production periods of maintenance interval $[0, T]$ which the maximum average number of failures equals to $\mathbf{1 4 , 8 3 6 3 4}$ and dispatching this quantity for the subcontracting. In this case, the maintenance cost to withdraw from total cost equals to $\overline{C(N, U)}=\mathbf{8 0 , 0 5} \mathbf{~ u m}$. From table 5, after the deleting of this quantity $(\Delta P=16)$, we noted that the production rates of the three first production periods are equal to zero. From equation 13, we obtained, for the calling of tender, that the subcontractor cost does not exceed $\mathbf{3 3} \mathbf{~ u m}$ in 
order to respect the EPMP optimization. For the second approach (ascending order) defined in table 6, we notice that the interval $[\mathrm{T}, 2 \mathrm{~T}]$ is the lowest of average failure and is equal to 9,98135 and for tender the subcontractor cost does not exceed $67 \mathrm{um}$. Comparing these two approaches, we can notice that first approach (descending order) is more interesting than second approach (ascending order) in terms of cost. This can be explained by the fact that, for descending order, from the start, we remove production from the maintenance intervals of largest average failure and in this case, we can reduce the pressure on the principal machine and it is logical that we find low production during this interval and consequently, the degradation degree of equipment decreases as well as the maintenance cost. On the other side, for ascending approach, we remove the production from the maintenance interval, which already has a low average number of failures, so it was not a great influence on the degradation of the machine and on maintenance cost as well as the subcontractor cost of tender.

Table 5: DESCENDING ORDER OF AVERAGE NUMBER OF FAILURE

\begin{tabular}{|c|c|c|c|}
\hline \multicolumn{4}{|l|}{$[0, \mathrm{~T}]: 14,83634$} \\
\hline $\mathrm{u}(0)=0$ & $\mathrm{u}(1)=0$ & $u(2)=0$ & $u(3)=9$ \\
\hline \multicolumn{4}{|c|}{$[4 \mathrm{~T}, 5 \mathrm{~T}]: 10,00198$} \\
\hline $\mathrm{u}(16)=12$ & $u(17)=9$ & $u(18)=3$ & $u(19)=7$ \\
\hline \multicolumn{4}{|l|}{$[3 \mathrm{~T}, 4 \mathrm{~T}]: 9,99766$} \\
\hline$u(12)=8$ & $\mathrm{u}(13)=10$ & $\mathrm{u}(14)=12$ & $u(15)=13$ \\
\hline \multicolumn{4}{|l|}{$[5 \mathrm{~T}, 6 \mathrm{~T}]: 9,99519$} \\
\hline $\mathrm{u}(20)=2$ & $u(21)=5$ & $u(22)=13$ & $u(23)=12$ \\
\hline \multicolumn{4}{|l|}{$[\mathrm{T}, 2 \mathrm{~T}]: \quad 9,98135$} \\
\hline $\mathrm{u}(4)=1$ & $u(5)=10$ & $u(6)=11$ & $u(7)=10$ \\
\hline
\end{tabular}

With: $\overline{C(N, U)}=80,05$ and

$$
\Delta Q_{c} \cdot C c+C_{p r} \cdot \Delta p+\overline{C(N, U)}+h \cdot \sum_{j=l+1}^{H}\{S(j)\}^{2}
$$

$\Delta P$

Table 6: ASCENDING ORDER OF AVERAGE NUMBER OF FAILURE

\begin{tabular}{|c|c|c|c|}
\hline \multicolumn{4}{|l|}{$[T, 2 T]: 9,98135$} \\
\hline $\mathrm{u}(4)=0$ & $u(5)=0$ & $u(6)=6$ & $\mathrm{u}(7)=10$ \\
\hline \multicolumn{4}{|l|}{$[5 \mathrm{~T}, 6 \mathrm{~T}]: 9,99519$} \\
\hline$u(20)=2$ & $u(21)=5$ & $u(22)=13$ & $u(23)=12$ \\
\hline \multicolumn{4}{|l|}{$[3 \mathrm{~T}, 4 \mathrm{~T}]: 9,99766$} \\
\hline$u(12)=8$ & $u(13)=10$ & $u(14)=12$ & $\mathrm{u}(15)=13$ \\
\hline \multicolumn{4}{|c|}{$[4 \mathrm{~T}, 5 \mathrm{~T}]: \quad 10,00198$} \\
\hline $\mathrm{u}(16)=12$ & $u(17)=9$ & $u(18)=3$ & $u(19)=7$ \\
\hline \multicolumn{4}{|l|}{$[0, T]: 14,83634$} \\
\hline$u(0)=0$ & $\mathrm{u}(1)=0$ & $\mathrm{u}(2)=0$ & $u(3)=9$ \\
\hline
\end{tabular}


With: $\overline{C(N, U)}=\mathbf{6 1 9 , 6 4} \quad$ and $\quad C_{s} \leq \frac{\Delta Q_{c} \cdot C c+C_{p r} \cdot \Delta p+\overline{C(N, U)}+h \cdot \sum_{j=l+1}^{H}\{S(j)\}^{2}}{\Delta P} \rightarrow \mathrm{Cs} \leq 67$

The advantages of Ecological Production and Maintenance Policy:

Firstly, the principle of the EPMP is to propose an efficient ecological production and maintenance strategy which determines an economical production plan (table 2) and an optimal maintenance strategy (figure 4) in order to satisfy a random demand under a given service level and respect the toxic emissions standards and requirements while maintaining high economic efficiency. According to the different numerical results, we can note the importance of the Ecological Production and Maintenance Policy (EPMP). Since the principle of this policy is to detect the periods when there is a largest number of failures for the machine and consequently a biggest degradation and therefore highest emissions of Carbon. This important degradation is the consequence of a large use of the machine and the manufacturing of a large quantity of products. Since the machine degradation degree is influenced by the variation of production rates from a period to another one and characterised by an analytical equation (equation 21), that shows the evolution of the machine failure rate according to its use respecting in the same time the continuity of the equipment reliability from a period to another one. From this equation, we determined the average number of failures, assuming that after each preventive maintenance action the equipment is on state "as good as new" and that a maintenance action may be applied during the production as it can be done at the end of the period. In this case, the solution is to reduce the pressure on the machine by subcontracting a part of the production quantities, providing that the cost of subcontracting will be more economical, in order to reduce the environmental tax and at the same time satisfy the customer demand. The economical cost of subcontracting equals to $C s \leq 33$, is given by relation (13) as a function related to the maintenance cost to be withdrawn from the total cost $\overline{C(N, U)}=80,05$ um corresponding to the different actions of maintenance during the $[0, \mathrm{~T}]$.

\section{Conclusion}

In this paper, a new control policy called Ecological Production and Maintenance Policy (EPMP), which integrates ecological aspects concerns in the production and maintenance control of manufacturing system satisfying a random demand, subjected to random failure and caused damaging emissions to the environment, is proposed. The originality of our contribution to this paper consists in considering a new ecological production and maintenance optimization strategy based on subcontractor solution in the context of a calling of tender taking into account the influence of production rates on degradation degree of equipment. More precisely, the EPMP optimization is established in the context where the system's failure rate depends on both time and production rate. We recall that the context of the influence of the production rate variation on the system degradation and consequently on the maintenance strategy is well developed in Hajej et al (2011). In fact, in their study, giving the random demand, the required service level, they have formulated and solved the corresponding linear-quadratic stochastic 
production/maintenance problem. In our study we deal with the same problem but under a new ecological constraint which must be respected with the ecological tax imposed by the relevant authorities. By comparing between two EPMP approaches, we obtained the best cost of subcontracting in order to respect the EPMP optimization.

Based in this type of problem that treated the production and maintenance optimization in a complex environment of manufacturing system, this works will have a significant impact on future studies in this context. Indeed, we can relax some assumptions presented considering an imperfect maintenance action, a quality, etc.

\section{Reference:}

[1] Dellagi, S., Rezg, N. and Uie, U., 2007. "Preventive maintenance of manufacturing systems under environmental constraints". International Journal of Production Research, 45 (5), 1233.

[2] Dahane M, Clementz C, Rezg N, 2010," Effects of extension of subcontracting on a production system in a joint maintenance and production context", Computers \& Industrial Engineering, 58(1):8896, DOI:10.1016/j.cie.2009.08.007.

[3] Ayed S., Dellagi S., Rezg N., 2012." Joint optimisation of maintenance and production policies considering random demand and variable production rate". International Journal of Production Research, vol. 50, Issue 23, p 6870-6885.

[4] Ali Ben-Salema, Ali Gharbi*, Adnène Hajji b, 2015, Environmental issue in an alternative production maintenance control for unreliable manufacturing system subject to degradation, Int J Adv Manuf Technol. DOI 10.1007/s00170-014-6454-7

[5] Battini, D., Persona, A., \& Sgarbossa, F., 2013. A sustainable EOQ model: Theoretical formulation and applications. International Journal of Production Economics, 149, 145-153.

[6] Chouikhi, H., Dellagi, S., \& Rezg, N. (2012). Development and optimisation of a maintenance policy under environmental constraints. International Journal of Production Research, 50(13), 3612-3620.

[7] Dellagi, S., Rezg, N. and Uie, U., 2007. "Preventive maintenance of manufacturing systems under environmental constraints". International Journal of Production Research, 45 (5), 1233.

[8] Dahane M, Clementz C, Rezg N, 2010," Effects of extension of subcontracting on a production system in a joint maintenance and production context", Computers \& Industrial Engineering, 58(1):8896, DOI:10.1016/j.cie.2009.08.007.

[9] Dobos, I., 1998. Production- inventory control under environmental constraints, International Journal of Production Economics, 56, 123- 131.

[10] Dobos, I., 1999. Production strategies under environmental constraints in an Arrow-Karlin model. International Journal of Production Economics, 59, 337-340.

[11] Dobos, I., 2001. Production strategies under environmental constraints: Continuous-time model with concave costs. International Journal of Production Economics, 71, 323- 330. 
[12] Hajej Z., Dellagi S., Rezg N., 2011. "Optimal integrated maintenance/production policy for randomly failing systems with variable failure rate" International Journal of Production Research, vol. 49, Issue 19, pp 5695-5712.

[13] Hajej Z., Dellagi S., and Rezg N., 2009. "An optimal production/maintenance planning under stochastic random demand, service level and failure rate". IEEE explore. Issue 22-25 Aug: 292-297. India.

[14] Hajej Z., Dellagi S., and Rezg N.,2012 "Joint optimisation of maintenance and production policies with subcontracting and product returns", Journal of Intelligent Manufacturing, doi 10.1007/s10845$\underline{012-0707-9}$

[15] Hajej, Z., N. Rezg, and A. Gharbi. 2014. "Forecasting and Maintenance Problem under Subcontracting Constraint with Transportation Delay." International Journal of Production Research. doi:10.1080/00207543.2014.911418

[16] Jaber, M.Y., Glock C.H., El Saadany A.M.A., 2013. Supply chain coordination with emissions reduction incentives. International Journal of Production Research, 51 (1), 69-82.

[17] Kenne, J. P., \& Gharbi, A., 2000. Production planning problem in manufacturing systems with general failure and repair time distributions. Production Planning \& Control, 11(6), 581-588.

[18] Li, S., and Gu, M., 2012. The effect of emission permit trading with banking on firm's productioninventory strategies. Int. J. Production Economics, 137, 304-308.

[19] Gharbi, A., Kenne, J.P., Hajji, A., 2006. Operational level-based policies in production rate control of unreliable manufacturing systems with setups. International Journal of Production Research, 44 (3), $\underline{545-567 .}$ 